ARTICLE

https://doi.org/10.1057/s41599-019-0380-0

\title{
Expertise in research integration and implementation for tackling complex problems: when is it needed, where can it be found and how can it be strengthened?
}

\author{
Gabriele Bammer (1D et al. ${ }^{\#}$
}

\begin{abstract}
Expertise in research integration and implementation is an essential but often overlooked component of tackling complex societal and environmental problems. We focus on expertise relevant to any complex problem, especially contributory expertise, divided into 'knowing-that' and 'knowing-how.' We also deal with interactional expertise and the fact that much expertise is tacit. We explore three questions. First, in examining 'when is expertise in research integration and implementation required?,' we review tasks essential (a) to developing more comprehensive understandings of complex problems, plus possible ways to address them, and (b) for supporting implementation of those understandings into government policy, community practice, business and social innovation, or other initiatives. Second, in considering 'where can expertise in research integration and implementation currently be found?', we describe three realms: (a) specific approaches, including interdisciplinarity, transdisciplinarity, systems thinking and sustainability science; (b) case-based experience that is independent of these specific approaches; and (c) research examining elements of integration and implementation, specifically considering unknowns and fostering innovation. We highlight examples of expertise in each realm and demonstrate how fragmentation currently precludes clear identification of research integration and implementation expertise. Third, in exploring 'what is required to strengthen expertise in research integration and implementation?,' we propose building a knowledge bank. We delve into three key challenges: compiling existing expertise, indexing and organising the expertise to make it widely accessible, and understanding and overcoming the core reasons for the existing fragmentation. A growing knowledge bank of expertise in research integration and implementation on the one hand, and accumulating success in addressing complex societal and environmental problems on the other, will form a virtuous cycle so that each strengthens the other. Building a coalition of researchers and institutions will ensure this expertise and its application are valued and sustained.
\end{abstract}

\footnotetext{
\#A full list of authors and their affiliations appears at the end of the paper.
} 


\section{Introduction}

\ nterdisciplinarity' and 'transdisciplinarity' are widely heralded as key to research addressing complex societal and environmental problems, such as reducing the gap between rich and poor, combating illicit drug use, controlling spiralling health care costs and achieving sustainable social-ecological systems (Gibbons et al., 1994; Jacob, 2015; Ledford, 2015; National Academy of Sciences, National Academy of Engineering and Institute of Medicine, 2005). In these situations, the terms 'interdisciplinarity' and 'transdisciplinarity' are used generically to indicate that different strands of disciplinary and other knowledge (e.g., from policy makers and affected communities) need to be brought together and acted upon. Implicit, but largely unrecognised, is required expertise in (1) research integration to develop a more comprehensive understanding of the problem and possible ways to address it and (2) research implementation to improve the situation.

Poor understanding of expertise needed for research integration and implementation makes assessing interdisciplinarity and transdisciplinarity difficult at all levels, including tenure and promotion applications, funding proposals, outcomes of research projects, and outputs of inter- and transdisciplinary centres and other institutions (British Academy Working Group on Interdisciplinarity, 2016; Bursztyn and Drummond, 2014; Klein and Falk-Krzesinski, 2017; Lyall, 2019; McLeisch and Strang, 2016). For example, inadequate understanding of what interdisciplinarity involves and how to assess it may explain why interdisciplinary grant applications have lower success rates than discipline-based proposals (Bammer, 2016a; Bromham et al., 2016; Reckling and Fischer, 2010).

It is tempting to blame reviewers for assessment problems, labelling them as hostile or ignorant. Instead, we argue that those researching complex societal and environmental problems must ensure that expertise in research integration and implementation is well articulated, accessible and useable. These tasks require a major effort, especially as defining 'expertise' is far from straightforward. Our aim is to lay foundations for further work by exploring three questions:

1. When is expertise in research integration and implementation required?

2. Where can expertise in research integration and implementation currently be found?

3. What is required to strengthen expertise in research integration and implementation?

We open a discussion rather than being prescriptive and provide enough detail to give the ideas substance while inviting input and further development by others practising research integration and implementation.

Our starting point is that complex societal and environmental problems are generally investigated by teams made up of disciplinary experts and increasingly they include stakeholders affected by the problem, as well as those in a position to do something about it. We argue that some team members must have expertise in research integration and implementation to effectively harness the contributions of the full team. In this article, we start to tease out what that expertise entails.

In doing so, our focus is expertise that is not specifically about the problem being tackled, therefore we leave to one side understanding of the problem itself, be it climate change, organised crime or some other complex issue. Instead we are interested in the required expertise in research integration and implementation that is relevant to tackling any complex societal or environmental problem.

We explore three components of such expertise. Most of our focus is on contributory expertise, which Collins and Evans
(2002, 2007) define as the expertise required to make a substantive contribution to a field. We divide contributory expertise into 'knowing-that' and 'knowing-how' (Gobet, 2015). For research integration and implementation, 'knowing-that' involves understanding what is required to deal with complex societal and environmental problems in an integrated way, such as knowing to look for interconnections with other problems and to explore political, economic, historical and other circumstances. 'Knowing-how' involves knowing which methods or processes to use in a particular context, along with skills in those methods and processes, such as building a model to describe the problem, or processes for engaging decision-makers in discussing research results. Of course, we acknowledge that knowing-that and knowing-how are in practice inseparable; nevertheless, distinguishing them helps us illuminate critical aspects of expertise in research integration and implementation.

Interactional expertise is a second component of expertise in research integration and implementation. This is the ability to understand disciplines, professional practice and community experience without being trained in those disciplines or professions or having lived in those communities (Collins and Evans, 2007). Interactional expertise is required to work effectively and knowledgeably with a team.

Third, contributory and interactional expertise are often tacit, in which case their inputs to thought and action are difficult to access and identify reflexively (Collins and Evans, 2007). Collins and Evans argue that expertise becomes tacit through the process of achieving expert status, which involves an internalisation of knowledge and skills, along with a fluidity in applying them. In this article we are also interested in tacit expertise as a component of learning-by-doing, which is a common way of achieving expertise in research integration and implementation. As we describe below, many researchers find themselves in roles requiring integration and implementation and develop skills on the fly without paying much conscious attention to them.

In opening up this discussion on expertise, our target audience is the many researchers who investigate complex societal and environmental problems and who are interested in the integration and implementation role. We want to kick-start a process of understanding and building expertise in research integration and implementation that involves newcomers through to established researchers. This scope is essential both to improving actionoriented research on complex societal and environmental problems and to recognising and rewarding properly those who undertake the integration and implementation.

As an authorship group, we illustrate, at a small scale, the challenges that this article seeks to highlight and address. Despite our common interests in research integration and implementation, we have not found it easy to articulate our own expertise. Further, many of us were not aware of each other's contributions until we came together as invitees at the 2013 First Global Conference on Research Integration and Implementation (Integration and Implementation Sciences, 2019a). That conference made evident the extensive array of integration and implementation expertise that has been developed for tackling complex problems and how much more effective research could be if it could draw on the full range, rather than a partial selection. Figuring out how to address these challenges has motivated our work on this article.

We start by identifying research tasks that lie outside the remit of traditional disciplines and that require expertise in research integration and implementation. We then identify three realms where such expertise currently resides, demonstrating that expertise is highly fragmented both within and across these realms. Members of the authorship group play leading roles in each of these realms. 
To overcome fragmentation and strengthen expertise, we propose building a shared knowledge bank of expertise. A knowledge bank would have several major benefits. It would strengthen relevant expertise by bringing together different ways in which research integration and implementation are conceived and put into practice. It would also make expertise more visible and accessible. Further, it would unite relevant individuals and groups enabling them to provide an authoritative voice to research policy makers and funders about properly recognising, valuing and evaluating the integration and implementation expertise required to deal with complex societal and environmental problems.

We highlight key challenges in developing a knowledge bank: compiling existing expertise, indexing and organising the expertise to make it widely accessible, and understanding and overcoming the core reasons for the existing fragmentation. We close by describing the potential for a virtuous cycle between establishing a knowledge bank of expertise in research integration and implementation and increasing success in tackling complex societal and environmental problems.

\section{Question 1: when is expertise in research integration and implementation required?}

Addressing complex societal and environmental problems requires specific expertise over and above that contributed by disciplines, but there is little formal recognition of what that expertise is or reward for contributing it to a research team's efforts. Our focus in this section is on tasks that require expertise in research integration and implementation, along with an indication of what that expertise involves, both in working with discipline-based experts and stakeholders and in dealing with the complexity of the problems.

The end points of research integration and implementation are to:

- develop a more comprehensive understanding of the problem, plus possible ways to address it, by integrating disciplinary and stakeholder perspectives, and

- support implementation of that understanding into evidenceinformed government policy, professional and community practice, business and social innovation and other measures.

How best to achieve these goals (e.g., sequentially or concurrently) and which perspectives and implementers to involve are part of the required expertise in research integration and implementation. Expertise is also required to manage different start points, in other words whether the research is initiated and defined by the researchers, implementers (e.g., government policy makers), stakeholders affected by the problem or a combination of these.

An indication of the expertise needed can be gained by considering the complex problem of illicit drug use. One important task is to identify-using an amalgamation of know-that contributory expertise and interactional expertise-relevant discipline-based researchers and stakeholders, each of whom has an important, but only partial, understanding of the problem. Useful disciplinary inputs may include knowledge about drug effects from pharmacologists, estimates of levels of use in the population from epidemiologists, impacts on property theft and other crime from criminologists, information about regulations and laws from legal experts, and analysis of how those laws came into being from historians. Additionally, contributions to understanding come from two main groups of stakeholders: those affected by the problem, such as illicit drug users, and professional groups dealing with the problem, such as treatment and other service providers, police officers, and policy makers. As well as identifying useful perspectives, expertise in research integration and implementation is required to integrate them (know-how expertise), which includes assessing where perspectives align and where they conflict, and finding a way through conflicts.

Expertise in research integration and implementation is also required to assess and combine suggestions for action, determine strengths and risks, and decide whether the suggestions need to be supplemented by new ideas elicited through processes to spark innovation. This generally needs contributory know-how expertise. Know-how expertise, complemented by interactional expertise, is also required to identify various implementation options (through government, business and/or civil society, and through policy and/or practice change), as well as suitable implementation pathways, which can range from effective communication strategies for presenting results to decision-makers to using cocreative processes with decision-makers from the outset.

Expertise in research integration and implementation also requires the ability to embrace the challenges posed by 'wicked problems' (Rittel and Webber, 1973), also referred to as 'messes' (Ackoff, 1974). These are core to what we refer to as 'complex'. (We eschew the terms 'wicked' and 'messes' because they are difficult to translate into other languages.) Based on our experience and key literature (Ackoff, 1974; Churchman, 1970; Cilliers, 1998; Horn and Weber, 2007; Midgley, 2000; Rittel and Webber, 1973; Ulrich, 1983), we propose five particular challenges that complex problems present and that need specific expertise in order to be understood and managed, and again illustrate them using the problem of illicit drug use, drawing on Babor et al. (2018), Ritter et al. (2017) and Stevens (2010).

\section{Delimiting the problem.}

Know-that expertise is required to understand that complex real-world problems have no natural boundaries and that problems have many disparate causes, which are tangled and not easily apparent or readily inferred. For example, prevention of illicit drug use needs to account for, among other things, the legacy of childhood sexual abuse, influences of popular culture, youthful rebellion and peer pressure. Know-that expertise also includes understanding that (1) addressing a single aspect of the problem causes changes in other aspects and may lead to the emergence of new issues, (2) the problem and the system in which it is embedded evolve and (3) from both a research and an action perspective, everything cannot be dealt with, so artificial but necessary boundaries must be set. Know-how and interactional expertise are then required to draw out (from disciplinary and stakeholder subject matter experts) what the relevant interconnections are, what issues may emerge, what changes are likely, as well as to help set effective boundaries around the problem.

2. Managing contested problem definitions.

Know-that expertise is required to appreciate that the various parties involved in a complex societal or environmental problem have different ideas about the 'real' problem and its causes. For example, some see illicit drug use as a crime that results from the failure of individuals to take responsibility for adhering to laws meant to protect them. Others perceive laws as the heart of the problem, driving growth of organised crime and preventing a relatively innocuous activity from being controlled by social and cultural norms. Still others argue that illicit drug use results from a brain disorder that requires medical treatment. Know-that expertise entails understanding that definitional challenges are intrinsic to any complex problem and can only be effectively dealt with by understanding the history of conflict around the problem and its impact on the 
ability of groups with different perspectives to trust, listen to, and engage with each other. Know-how expertise, in turn, is needed to interact with different perspectives, to manage conflicts among them, and to provide an understanding of how they may affect decisions taken.

3. Managing critical, unresolvable unknowns.

Appreciating that it is not possible to know everything about a complex real-world problem is another dimension of know-that expertise. First, not everything that could be known will be investigated, because there is not enough research capacity, funding or interest to address every conceivable, and potentially important, question. Second, some critical issues cannot be researched effectively. For example, there are few feasible entry points for examining links among illicit drug use, organised crime and funding for terrorism. Third, interpretations of available information often conflict. Know-how expertise is then required to identify and chart a way of managing unknowns, so that they do not lead to adverse unintended consequences or nasty surprises.

4. Managing real-world constraints on ameliorating the problem.

Know-that expertise is required to appreciate that ideological, cultural, political, economic and other circumstances constrain how any complex real-world problem can be tackled, and also limit the influence of research-based evidence. In addition, options for moving forward are often hampered by current ways of managing the problem and may change the distribution of benefits and losses amongst the parties involved. Further, effectively addressing the problem often requires action across multiple poorly connected organisations. Know-that expertise therefore includes awareness of generic factors that play out in specific ways depending on the problem at hand. Such factors include the impact of laws and international treaties (which e.g., restrict options for action on illicit drugs), the importance of resources (where shifting resources, e.g., between law enforcement and health, can be challenging) and the necessity and difficulties of multi-sector collaboration (e.g., across law enforcement, health, social welfare and education). Know-that expertise is also required to appreciate that the multi-faceted circumstances in which a problem is embedded can make it resistant to change, as well as that those involved in dealing with the problem are likely to disagree about which constraints are open to modification. Know-how expertise, for its part, is required to find openings for doing things differently and to overcome resistance to change.

5. Appreciating and accommodating the partial and temporary nature of solutions.

Finally, know-that expertise is required to understand that no effort to tackle a complex real-world problem can take all aspects of complexity into account and that any way of moving forward will cause changes in interconnected problems, sacrifice a way of seeing the problem that some stakeholders want to preserve or even hold as nonnegotiable, open the door to adverse unintended consequences and miss some real-world constraints. It also requires appreciation that the search is for best-possible or least-worst, rather than definitive, solutions. Know-how expertise is required to identify and address these limitations to understanding and action.

Given that complex societal and environmental problems are generally investigated by teams made up of disciplinary experts and stakeholders, an important question is 'who in the team needs to have research integration and implementation expertise?'. We do not explore this question in detail here, noting that one of us (Bammer, 2013) has written about the advantages of developing a new discipline of Integration and Implementation Sciences (i2S) that would train experts in research integration and implementation as members of teams tackling complex problems.

In any case, identifying the range of expertise required and systematically considering how to include it in teams tackling complex societal and environmental problems will be an advance on the current shortcomings that stem from teams tending to rely on the happenstance of what their members know, are interested in, and consider to be important.

\section{Question 2: where can expertise in research integration and implementation currently be found?}

We have identified three major realms where expertise in research integration and implementation can be found and how they correspond (or not) to communities of researchers. First, some researchers apply specific approaches to tackling complex societal and environmental problems, such as interdisciplinarity, systems thinking, and action research. These approaches have coalesced around particular ways of understanding and operationalising research integration and implementation. Each community practising a specific approach is largely independent of the others.

Second, some researchers develop case-based experience without reference to specific approaches and, by moving from one problem to another, progressively build useful know-that and know-how expertise (often tacit) in research integration and implementation, along with interactional expertise. From time to time they may incorporate know-that and know-how developed by others into their practice. Unlike researchers using specific approaches, researchers drawing primarily on case-based experience tend not to be organised into communities around expertise in research integration and implementation, although they may be organised into communities around the problems of interest. We recognise that the communities using specific approaches to complex societal and environmental problems also work on cases (see for example Fulton et al. (2014) for a case using complex systems science and Neuhauser (2018) for a case using transdisciplinarity), but that is tangential to the point we make here.

The final source of expertise comes from researchers who investigate an element of research integration and implementation and who are not aligned with either of the other realms. We focus here on two examples-researchers interested in unknowns and those interested in innovation. In both cases, researchers come from various disciplinary and professional backgrounds. These examples differ in the strength of the associated community (measured by regular conferences and publishing in specific journals), which is weak in the case of unknowns and stronger for innovation. In both cases, interest in unknowns or innovation is not specifically focused on complex societal and environmental problems and the relevance of their insights to research integration and implementation may not be immediately obvious.

Of course, the three realms do not have hard boundaries and researchers may identify with different realms at different times in their careers. The point of identifying these three realms where expertise in research integration and implementation exists is to highlight both the existing fragmentation, as well as which veins need to be tapped into to draw together what is already available, especially in relevant know-that and know-how contributory expertise, and to illustrate where interactional expertise and tacit expertise are important. 
Specific approaches. One rich source of insights into expertise in research integration and implementation can be found in what we call specific approaches. The lists in Box 1 come from a sub-group of the authors who drew on several centuries of combined experience and scholarship, as well as their roles in helping develop some of these approaches (marked with an 'a').

The first column in Box 1 records 14 approaches that provide a wide range of expertise across both research integration and implementation. These approaches include action research, integrated assessment and post-normal science. The ten approaches in the second column provide a subset of expertise in research integration and implementation. Some provide expertise in research implementation only (change management, impact assessment, impact evaluation, implementation science, $\mathrm{K}^{*}$ and policy science). Others provide expertise across both research integration and implementation, but only for a specific set of activities, rather than the broad range of expertise provided by the approaches listed in the first column. In particular, three approaches provide expertise in decision making and/or dealing with risk (decision making under deep uncertainty, decision sciences and risk analysis) and one in collaboration (science of team science). Multiple related approaches are listed under one specific approach in each column, namely systems thinking and $\mathrm{K}^{\star}$. Many other approaches encompass various schools of thinking as well, but these have not split into separate but related approaches.

While we have listed all the specific approaches we are aware of, we anticipate that this list is not complete and that there are elements which could be contested. Further, we have not aimed to be comprehensive in the cited references, but rather have provided a major work (occasionally more) as a starting point for those interested in learning about each approach.

Before proceeding, it is important to recognise that the terms 'interdisciplinarity' and 'transdisciplinarity' are used in two

Box 1 | Specific approaches to tackling complex real-world problems, divided into those that provide wide-ranging expertise in both research integration and implementation and those that provide expertise in a subset of research integration and implementation activities

\section{Approaches providing wide-ranging expertise across both research integration and implementation}

Action research ${ }^{a, 1}$

Complex project management ${ }^{\mathrm{a}, 2}$

Complex systems science ${ }^{3}$

Design science $\mathrm{a}^{\mathrm{a}} 4$

Integrated assessment ${ }^{a, 5}$

Integration and implementation sciences ${ }^{a, 6}$

Interdisciplinarity $\mathrm{a}, 7$

Mode $2^{8}$

Operational research ${ }^{9}$, including community operational research ${ }^{\mathrm{a}, 10}$

Post-normal science ${ }^{11}$

Sustainability science ${ }^{\mathrm{a}, 12}$

Sustainability transitions ${ }^{13}$

Systems thinkinga, including systems analysis ${ }^{a}{ }^{14}$, systems engineering ${ }^{15}$, the viable system model ${ }^{16}$, systems failure ${ }^{17}$, soft systems thinking ${ }^{18}$,

critical systems thinking ${ }^{19}$, system dynamics ${ }^{a}, 20$ (including participatory

system dynamics ${ }^{\mathrm{a}, 21}$ ) systemic intervention ${ }^{\mathrm{a}, 22}$

Transdisciplinaritya,23

${ }^{1}$ Bradbury, 2015

2 Cicmil et al., 2009

3 Mitchell, 2009

4 Simon, 1996

5 Rotmans and van Asselt, 1996

6 Bammer, 2013

7 Klein, 1990; 2010

8 Gibbons et al., 1994

9 Taha, 2017

10 Johnson, 2012; Midgley and Ochoa-Arias, 2004

11 Funtowicz and Ravetz, 1993

12 Clark and Dickson, 2003

13 Loorbach et al., 2017

14 Miser and Quade, 1985; 1988

15 Hall, 1962

16 Beer, 1984

17 Fortune and Peters, 1995

18 Ackoff, 1981; Checkland, 1981; Churchman, 1979

19 Flood and Jackson, 1991; Flood and Romm, 1996

20 Forrester, 1961; Sterman, 2000

${ }^{21}$ Richardson and Andersen, 2010; Vennix, 1996

22 Midgley, 2000

23 Bergmann et al., 2012; Hirsch Hadorn et al., 2008; Jahn et al., 2012; Vilsmaier et al., 2017
Approaches providing expertise for a subset of research integration and implementation activities

\section{Research implementation only}

Change management 24

Impact assessment ${ }^{25}$

Impact evaluation 26

Implementation science 27

$\mathrm{K}^{\star}$ (KStar) including Knowledge brokering, Knowledge exchange, Knowledge management, Knowledge mobilisation, Knowledge transfer, Knowledge translation ${ }^{28}$

Policy science 29

Specific subset of research integration and implementation

Decision making under deep uncertainty 30

Decision sciences ${ }^{31}$

Risk analysis ${ }^{32}$

Science of team science ${ }^{a, 33}$

24 Nauheimer, 1997

25 Therival and Wood, 2018

26 Gertler et al., 2016

27 Eccles et al., 2009

28 Shaxson et al., 2012

29 Cairney and Weible, 2017

30 Marchau et al., 2019

31 Kleindorfer et al., 1993

32 Aven, 2012

33 National Research Council, 2015

aApproaches that members of the authorship group have helped develop 
different ways in the literature. In the introduction we used them in the generic sense for any research that brings together different strands of disciplinary and other knowledge and supports action based on this improved understanding. Now, unless otherwise specified, we use the second connotation, which refers to specific research approaches with established canons of scholarly work. It is also worth noting that in its specific sense, the term transdisciplinarity is used in multiple ways, including the development of new theoretical paradigms (e.g., general system theory) and methodologies that transcend disciplinary boundaries; critiques of existing structures of knowledge; building new integrative frameworks and research strategies; and involving stakeholders in both research on complex problems or phenomena and the implementation of solutions. The definition we use is provided in Box 2.

Specific approaches have at least one of the following characteristics:

- they are associated with one or more professional associations or networks, and often with peer-reviewed journals and conferences; and

- handbooks or other major academic works describe them.

Three examples, two from the first column in Box 1 and one from the second column, provide an illustration, while also demonstrating the different stages of development of these three approaches and the high level of fragmentation in the systems thinking community.

\section{Box 2 I Examples of expertise from four specific approaches: interdisciplinarity, sustainability science, systemic intervention and transdisciplinarity. Brief descriptions of the approaches are also provided, along with when the expertise described is useful in tackling complex societal and environmental problems}

Interdisciplinarity is a mode of research and problem-solving that integrates information, methods, tools, concepts, and/or theories from two or more disciplines. Activities range from individual borrowing of techniques across disciplines to large-scale collaborative initiatives. Differences in practice and theory include narrow versus broad scope, and methodological versus theoretical goals (Klein, 1990; 2010). The example of expertise described next is relevant to team-based collaborations.

Example: 'Toolbox' dialogue method to uncover research worldviews

Know-that expertise involves appreciating that worldviews frame what investigators see, what priorities they set, how they talk, and how they act. Know-how expertise employs a technique that uses prompts grounded in concepts and methods drawn from epistemology and the philosophy of science to structure dialogue among collaborators (O'Rourke and Crowley, 2013). The prompts supply common ground on which collaborators can stand when discussing the nature of their particular project (Toolbox Dialogue Initiative, 2019).

This expertise is useful for: allowing researchers from different disciplines to understand their differences as a key ingredient for working together effectively.

Sustainability science deals with 'interactions between natural and social systems, and how those interactions affect the challenge of sustainability: meeting the needs of present and future generations while substantially reducing poverty and conserving the planet's life support systems' (PNAS, 2019). Approaches to sustainability vary in purposes, scales, ideologies, epistemologies, and theoretical constructs (O'Connell et al., 2013). Sustainability science expertise requires know-that understanding of resilience, adaptation and transformation, which are central concepts. One example of expertise follows.

Example: Adaptation pathways to develop and sequence decisions and actions

Know-that expertise requires understanding that values, knowledge and rules shape an evolving decision context (Gorddard et al., 2016). Know-how is required to help stakeholders envisage a range of alternative futures and their associated system drivers, along with eliciting the relevant values, knowledge and rules. Know-how is further required to use this shared understanding to map multiple possible pathways into the future, to characterise sequences of plausible actions, and to identify triggers and criteria for decision points for switching from one pathway to another (e.g., Frantzeskaki et al., 2019; Maru et al., 2017).

This expertise is useful for: managing real-world constraints on ameliorating the problem and appreciating and accommodating the partial and temporary nature of solutions.

Systemic intervention starts with specific expertise in boundary critique to analyse issues of inclusion, exclusion, marginalisation, conflict and power relations. This then informs the choice of other methods for intervention, involving creative mixing from the full range of systems, social and biophysical sciences or designing new methods (Midgley, 2000)

Example: Boundary critique

Boundary critique involves know-that and know-how to specifically engage participants in systemic thinking about how things ought to be and not just how they currently are. Know-how is required to explore stakeholders' purposes, values and framings of the problem situation through conversations, interviews and/or workshops, as well as to use theory-informed diagramming tools to help identify and address processes of conflict, marginalisation and associated stigmatisation that can inhibit both stakeholder participation and systemic thinking (Midgley, 2000).

This expertise is useful for: delimiting the problem, especially taking power relations into account in the process of boundary exploration and setting. Transdisciplinarity involves trans-sector participation of stakeholders in both research on complex problems and implementation of solutions. This typically involves multiple disciplines, fields and professions in teams that co-design research, co-produce solution-oriented knowledge, and reintegrate the knowledge into strategies for problem-solving and the development of new scientific insights (Hirsch Hadorn et al., 2008; Jahn et al., 2012; Pohl and Hirsch Hadorn, 2007). We present two examples of relevant expertise.

Example 1: 'Three types of knowledge' tool

Know-that expertise involves understanding that three types of knowledge are fundamental to transdisciplinary research: knowledge about what is (systems knowledge), knowledge about what should be (target knowledge), and knowledge about how to get from 'what is' to 'what should be' (transformation knowledge). Know-how expertise involves being able to guide research teams through a process of considering how their investigations will provide each of the three types of knowledge (Pohl and Hirsch Hadorn, 2007; td-Net, 2019).

This expertise is useful for: highlighting that producing a more comprehensive understanding of the problem and supporting action require different types of knowledge.

Example 2: Formulating hypotheses to develop a group model of the problem

Know-how expertise is required to guide all members of a research team-disciplinary experts and stakeholder representatives-in articulating why they think the problem under investigation exists, followed by discussing similarities and differences among these hypotheses with the aim of developing a simple system model that describes the problem and accommodates the ideas of the whole group (Bergmann et al., 2012).

This expertise is useful for: managing contested problem definitions. 
- Systems thinkers, systems scientists and systems engineers have formed many international associations, including the Complex Systems Society; the IEEE (Institute of Electrical and Electronics Engineers) Systems Council; the IEEE Systems, Man and Cybernetics Society; the International Council on Systems Engineering; the International Federation for Systems Research; the International Society for Knowledge and Systems Sciences; the International Society for the Systems Sciences; the System Dynamics Society; and the World Organisation of Systems and Cybernetics. There are also numerous national bodies. Most societies run annual conferences. Journals include Cybernetics and Systems; International Journal of General Systems; International Journal of Knowledge and Systems Sciences; System Dynamics Review; Systemic Practice and Action Research; Systems; and Systems Research and Behavioural Science. Major reference works include an encyclopaedia (François, 2004) and various volumes of classic and contemporary reprints covering the whole field (Beishon and Peters, 1972; Buckley, 1965; Emery, 1969, 1981; Midgley, 2003).

- Interdisciplinarians have formed the Association for Interdisciplinary Studies and Intereach (Interdisciplinary Integration Research Careers Hub). The Association for Interdisciplinary Studies publishes the journal Issues in Interdisciplinary Studies and runs an annual conference. The Oxford Handbook of Interdisciplinarity (Frodeman, 2017) is now in its second edition.

- Proponents of the science of team science have formed an International Network for the Science of Team Science and manage a listserv and annual conference. The major reference, produced in the US, is a report by the National Research Council (2015).

A detailed list of professional associations and networks, along with their journals and conferences, is available for most specific approaches at Integration and Implementation Sciences (2019b).

It is beyond the scope of this article to review these approaches. Instead, the aim of the lists in Box 1 is to demonstrate that there are many specific approaches that can provide know-that and know-how contributory expertise. Teasing out that expertise is a task for future research.

In Box 2 we describe examples of contributory expertise drawing on some of the specific approaches that we know best: interdisciplinarity, sustainability science, systemic intervention and transdisciplinarity. For each example of contributory expertise (e.g., the 'three types of knowledge tool' developed in transdisciplinary research) we also briefly describe when that expertise would be useful, referring back to the issues raised in addressing Question 1 (When is expertise in research integration and implementation required?). At this stage, we have not attempted to be systematic or detailed, but instead have aimed to highlight examples of expertise that we expect will resonate with our target audience. For this reason we focus on contributory expertise, except for Box 3 below. We also want to provide a sense of what compiling expertise will involve and that this compilation task is ripe for further work.

Case-based experience that is independent of specific approaches. Many researchers investigating complex real-world problems build their expertise by tackling particular problems without any real appreciation of the know-that and know-how offered by the specific approaches described above. This casebased expertise involves learning-by-doing and is generally augmented from project to project. Some codify the expertise they develop, while for others it remains largely tacit knowledge.
In Box 3 we provide brief descriptions of case-based expertise developed by members of the authorship group. This provides an opportunity to highlight both interactional expertise (usually tacit) and tacit contributory expertise, which are easier to identify in case-based experience than in the other realms. For each case we describe the aims of the research, along with the outcomes of the research integration and research implementation. We then highlight which disciplines and stakeholders were involved, requiring interactional expertise to effectively draw on their contributions. Finally, we highlight examples of the tacit contributory expertise developed in addressing the problem. That tacit expertise was made explicit through the process of writing this article.

As an aside, reviewing both Case 1 and Box 2 illustrates that researchers can move between realms. One of us (O'Connell) used the experience gained in case-based research to subsequently contribute to the development of sustainability science.

In Box 4, we describe two examples of codified expertise developed from case-based experience. The first example is a compilation of collaboration methods largely based on lessons learnt in resolving conflicts among researchers at the US National Cancer Institute (Bennett et al., 2018). From this compilation we specifically describe a set of know-that understandings that can be used to underpin 'pre-nuptial' agreements for research collaborators. The second example comes from a wide array of projects undertaken by the RAPID (Research and Policy in Development) programme of the UK's Overseas Development Institute, which led to the development of a toolkit for engaging and influencing policy (Young et al., 2014), from which we describe one knowhow method (alignment, interest and influence matrix).

Elements of research integration and implementation: considering unknowns and enhancing innovation. Expertise for tackling complex societal and environmental problems also comes from investigations on specific elements of research integration and implementation undertaken by researchers who are not involved in developing specific approaches or case-based experience. Here, we review expertise developed in research on unknowns and on enhancing innovation as two examples. We particularly emphasise considering unknowns, which is an area that is generally poorly understood and under-researched (Smithson, 1989), despite its critical importance in dealing with complex problems. Enhancing innovation is also of major importance in finding new, creative ways for understanding and acting on complex societal and environmental problems. These are also areas in which two of our authorship group specialise. Of course, expertise in considering unknowns and enhancing innovation can also be developed by those involved in specific approaches and case-based experience, but this is tangential to the point we aim to make here.

In Box 5, we provide two examples of know-that and three examples of know-how expertise developed by researchers considering unknowns. The first example of know-how is a compilation of strategies for accepting unknowns, while the other two are specific methods. In Box 6, we present two examples of know-that expertise and one of know-how expertise developed by researchers considering innovation. In both boxes, we also indicate when this expertise is required in tackling complex societal and environmental problems, referring back to the matters raised in addressing Question 1 (When is expertise in research integration and implementation required?).

Next steps. Making an inventory of expertise in each of the three realms is beyond the scope of this article, but, as we argue in the next section, is a first step in strengthening expertise in research 
Box 3 | Three examples of cases tackling complex societal or environmental problems, which led to the development of tacit contributory and interactional expertise in research integration and implementation

CASE 1. Assessing the potential for biomass to provide sustainable bioelectricity and biofuels, and greenhouse gas emission reduction in Australia (2005-2016) (Crawford et al., 2016; Farine et al., 2012; Hayward et al., 2015; O'Connell et al., 2009)

Aim: (1) to provide credible quantification of benefits, sustainability impacts and opportunities of biofuels, (2) to assess a range of emerging technology options and (3) to provide reliable knowledge upon which industry and government could base their decisions.

Research integration outcomes: research findings were integrated across multiple value chains, multiple industry sectors and different types of emerging technology, aquatic and terrestrial production systems, time periods from current to future, different types of stakeholders, and local to global scales. Research implementation outcomes: project results influenced positions of various stakeholders and their investments: the blueprint for aviation industry targets and commitments (Graham et al., 2011), national research and development plans for Australia (Bioenergy Research, Development and Extension Advisory Forum and Technical Working Groups, 2014; O'Connell and Haritos, 2010; O'Connell et al., 2007) and the international standard for sustainability 'Sustainability Criteria for Bioenergy' ISO 13065:2015 (International Standards Association ISO, 2015).

Interactional expertise was required to work with the disciplines of: agriculture, forestry, hydrology, greenhouse gas accounting, process engineering, chemistry, biochemistry, mathematics, economics.

Interactional expertise was required to work with stakeholders from: energy, agriculture and forestry sectors; aviation; companies and large global corporations; state and national governments; non-government organisations, including World Wildlife Fund and Australian Conservation Foundation; international governments; and various local communities.

Example of tacit know-that: Knowledge about the necessity to look for different delimitations and definitions of the problem being addressed among the multiple groups involved.

Example of tacit know-how: Skills to work with different stakeholder groups in different ways to support the research implementation. For example, changing the international standard involved attending standard-setting meetings and being hands-on in the trade-offs and wordsmithing involved.

CASE 2. Reducing air pollution and improving health in Jakarta, Indonesia (2004-2009) (Haryanto, 2013)

Aim: to provide scientific evidence about health impacts caused by air pollution and to develop a first-stage 'academic draft' of a provincial regulation for reducing air pollution.

Research integration outcomes: first comprehensive assessment of main air pollutant exposures and effects on human health in Indonesia.

Research implementation outcomes: the research underpinned a Jakarta provincial regulation on air quality and a decree issued by the Governor on indoor air quality.

Interactional expertise was required to work with the disciplines of: epidemiology, environmental health, pharmacology, public health nutrition, environmental engineering.

Interactional expertise was required to work with stakeholders from: Ministry of Environment, provincial health office, 20 private companies, Government of Jakarta, 28 elementary schools in Jakarta, Jakarta Metropolitan Office, private car and public transport commuters, international non-government organisations, and an international nutritional supplement company.

Example of tacit know-that: Knowledge about the role of provincial regulations and where research findings would be appropriate.

Example of tacit know-how: Skills in acting as a policy entrepreneur and seizing opportunities for effecting change.

CASE 3. Developing policies on medical tourism in Thailand (2010, not documented)

Aim: to find an appropriate balance between competing private and public demands on health workers and other resources caused by 'medical tourism' in Thailand, as well as how the private and public health sectors can collaborate to improve the health of the Thai population. Medical tourism generates substantial revenue from foreign patients and is promoted by the private health sector with political support from the government. Significant concerns arise, however, about inadequate public health provision for the Thai population.

Research integration outcomes: evidence from several studies, expert opinion, and findings from a public hearing were combined to develop a resolution for the National Health Assembly.

Research implementation outcomes: the National Health Assembly adopted the resolution in December 2010 (Third National Health Assembly, 2010) and the cabinet of the Thai government endorsed it in April 2011.

Interactional expertise was required to work with the disciplines of: public health, economics, sociology, medicine.

Interactional expertise was required to work with stakeholders from: Ministry of Public Health, Regional and General Hospital Society, Rural Doctors Society, Private Hospital Association, health professional councils (medical, dental and nursing), University Hospital Networks-Thailand (medical schools), civil society organisations, Ministry of Commerce, relevant areas of the law, constituencies of the National Health Assembly.

Example of tacit know-that: Knowledge about the mechanics of the political process.

Example of tacit know-how: Skills to identify the powerful players who needed to be on board and to interact effectively with them in finding ways of responding to their concerns.

integration and implementation. We have set out to provide enough examples to demonstrate that considerable expertise already exists and to provide an indication of the effort required for an effective compilation exercise. In both this and the previous section, we have also aimed to provide a sense of the extent and diversity of the expertise required for effective research integration and implementation. On the other hand, there is also considerable overlap in know-that and know-how expertise developed by different communities and groups, which also has to be dealt with in any compilation exercise.

\section{Question 3: what is required to strengthen expertise in research integration and implementation?}

Key to strengthening expertise in research integration and implementation is to make it readily identifiable and accessible.
As little effort has gone into documenting such expertise, it is largely invisible and unrecognised. Further, as we have shown in the previous section, it is also highly fragmented. It is, therefore, currently much easier for researchers and teams to 'reinvent the wheel' by duplicating know-that and know-how than to find, build on and improve existing expertise.

Identifying expertise and overcoming fragmentation are therefore critical, requiring both an inventory and an organisational framework that promotes accessibility. Both requirements could be achieved by building a dynamic, shared knowledge bank and here we outline what is involved.

The scale of a knowledge bank would be considerably greater than a toolkit, and indeed, many toolkits would be included in the knowledge bank. In order to avoid consignment to a graveyard of integrative databases, atlases, and knowledge compendiums that have not gained traction, the knowledge bank requires 
Box 4 | Two examples of codified expertise from cased-based experience developed independently of specific approaches, plus when this expertise is helpful

\section{Pre-nuptial agreement for research collaborators}

Know-that expertise includes understanding that collaboration can be assisted by addressing expectations and areas of potential conflict at the outset, specifically considering (1) overall goals and outcomes; (2) who will do what, including how personnel decisions are made, supervision is provided and data are managed; (3) authorship and credit, including giving public presentations, responding to media inquiries and managing intellectual property; (4) contingencies and communication, including management of team communication, new collaborations and spin-off projects, departures or changes of key personnel and modification of the research agenda by new discoveries or unexpected outcomes; and 5) identifying and addressing conflicts of interest (Bennett et al., 2018).

This expertise is useful for: opening discussion about issues that could cause conflict in collaboration and setting in place proposed resolutions.

\section{Alignment, interest and influence matrix}

Know-how expertise includes being able to use a four-dimensional stakeholder mapping tool to identify with whom researchers should engage for their work to have policy impact. The first two dimensions-degree of alignment with the policy direction emerging from the research and degree of interest in the policy issue-sort stakeholders into those with whom the project should seek to collaborate, those to co-opt, those to challenge, and those who can be ignored. Leaving aside the last group, the two next steps in the process are to identify those with power and those with whom it is possible to engage directly (Mendizabal, 2010; Young et al., 2014).

This expertise is useful for: prioritising which stakeholders to work with and how to work with them.

\section{Box 5 | Examples of expertise in research integration and implementation specifically relevant to considering unknowns. Brief} descriptions of when this expertise is useful are also provided

\section{Social construction of ignorance}

Know-that expertise includes appreciating that ignorance is usefully considered as socially constructed rather than somehow imposed by a complex universe (Smithson, 1989). Further, people may strategically construct and impose unknowns on others through, for example, intellectual suppression and 'undone science' (e.g., topics that are not funded; Hess, 2016) or by manufacturing doubt (Michaels, 2008; Oreskes and Conway, 2010).

This expertise is useful for: better appreciating the complexity of unknowns.

\section{Recognising different kinds of unknowns}

Know-that expertise recognises different kinds of unknowns and taxonomies of unknowns differentiating, for example, 'what we are ignorant of' from 'what we choose to ignore', or distinguishing 'error' from 'vagueness' (Smithson, 1989). Humans operate differently depending on the kind of unknown they are dealing with, so that addressing different unknowns requires different know-how strategies. For example, people are generally more averse to and distrustful of unknowns arising from conflicting information than unknowns arising from ambiguity or vagueness (Smithson, 1999).

Unknowns can also be differentiated into 'known unknowns' (where disciplines generally put their efforts), 'unknown knowns' (tacit knowledge) and 'unknown unknowns' (Kerwin, 1993). The last of these can be particularly hard to recognise and handle. Finally, unknowns can be approached from the perspective of a particular complex real-world problem, which can highlight unknowns at intersections of disciplines, unknowns that are not in the purview of any discipline but that concern stakeholders, and unknowns marginalised by power relations (Bammer, 2016a).

This expertise is useful for: better appreciating the complexity of unknowns, especially those that may be critical and unresolvable.

\section{Accepting unknowns}

Know-how expertise includes strategies to accept that unknowns exist and to diminish the risk of adverse unintended consequences, or at least limit their impact. Examples include practicing adaptive management (Holling, 1978; Hughes et al., 2007), building in resilience (Biggs et al., 2015), adopting the precautionary principle (de Sadeleer, 2007; Kriebel et al., 2001) and differentiating high-risk from low-risk unknowns in strategic choice processes (Friend and Hickling, 2005). Acceptance strategies tend to prefer trust-based relations over contractual ones, and prioritise robustness and satisficing over optimisation, identifying options worth preserving (Smithson and Ben-Haim, 2015).

This expertise is useful for: managing critical, unresolvable unknowns.

\section{Info-gap theory}

Know-how expertise also includes facility with processes such as info-gap theory, which starts with a model for the situation, where some parameters or model structures are unknown. Estimates of the unknowns are then taken; they are assumed to be substantially wrong, and analysis involves determining how sensitive outcomes under the model are to the errors in these estimates (Ben-Haim, 2006).

This expertise is useful for: managing critical, unresolvable unknowns.

\section{Learning plan method}

Know-how expertise involves ability to employ methods such as learning loops, which can be used to resolve unknowns and discover unforeseen unknowns. The first step is to define what to do next. Sources of unknowns are identified and categorised by the importance of resolving them immediately. One source of unknowns is selected, an assumption about the unknown formulated and a test of the assumption designed. The next step is to test the assumption. The third step is to evaluate the information and knowledge gained through the test, including whether any new unknowns emerged. This then informs the next iteration of the loop (Rice et al., 2008).

This expertise is useful for: managing critical, unresolvable unknowns.

wide-ranging support from the realms where expertise currently resides. Building a knowledge bank therefore also involves building a coalition of key communities and teams. Such a coalition will, through the process of building the knowledge bank, provide an authoritative voice about expertise in research integration and implementation, ensuring that it is properly valued. In turn this will improve assessments of integration and implementation in research tackling complex societal and environmental problems, including in tenure and promotion applications, funding proposals, outcomes of research projects, and outputs of inter- and transdisciplinary centres and other institutions.

We review three key challenges involved in building a knowledge bank: compiling existing expertise, indexing and organising the expertise to make it widely accessible, and understanding and overcoming the core reasons for the existing fragmentation. For each we also highlight some current-positive trends. The aim is to provide an indication of the effort that is 
Box 6 | Examples of expertise in research integration and implementation specifically relevant to enhancing innovation. Brief descriptions of when this expertise is useful are also provided

\section{Differentiating adoption from use}

Know-that expertise includes understanding that adoption differs from use. Adoption is the willingness and ability to take research results and embody them into something more broadly useable, such as a manufactured product, a policy or an implementation programme. Use focuses on the receiving ecosystem of people and organisations, who use what the adopter has created and thereby change their behaviour-i.e., do something new-indicating research impact. Adopters and users have different motivations, which must be recognised and taken into account by those developing research implementation expertise (Adner, 2012; Elsum, 2013).

This expertise is useful for: understanding the processes required to make change happen.

\section{Innovation through searching for ideas, information and knowledge}

Know-that expertise includes understanding that the search strategy used for ideas, information or knowledge will determine whether an innovation is incremental, involving minor changes to established ways of working, or radical, involving major, even fundamental, changes. Radical innovation enables previously intractable problems to be tackled, though it requires individuals and organisations to step outside their existing cognitive frames and/or search strategies (Dorst, 2015; Nicholas et al., 2013). Reframing and a broad search strategy increase the likelihood of being able to combine elements from distinctly different existing ways of doing things. Such recombination can be a source of novel ideas with high impact (Fleming, 2007; Savino et al., 2017).

This expertise is useful for: developing new ways for tackling complex societal and environmental problems.

\section{Using analogy to spark innovation}

Know-how expertise includes being able to use analogy to spark innovation. Effective use of analogy requires drawing on knowledge of solutions in a familiar domain and applying them to an unfamiliar domain. Unfamiliarity in the application domain reduces constraints arising from unconsciously sticking to mental models and problem-solving strategies that have been helpful in the past, which impedes sparking of highly novel solutions.

Developing non-obvious analogies requires identification of deep similarities in relational characteristics of the domains. This is typically stimulated by a specific problem and involves a high level of abstraction (Gassmann and Zeschky, 2008).

This expertise is useful for: developing new ways for tackling complex societal and environmental problems.

required, especially from those in the three realms who need to be involved for a knowledge bank to be a long-term success.

Compiling existing expertise. Compiling existing expertise is a major task and we have aimed to lay foundations in this article by addressing three key issues:

\section{- defining expertise}

- identifying tasks requiring expertise in research integration and implementation

- describing expertise, which also needs to incorporate illustrative examples and guidance for when the expertise is appropriate (relating back to the tasks requiring expertise).

In focusing on the third of these-describing expertise-we identify five major challenges. One immediate challenge is finding relevant expertise and illustrative case studies, many of which are not documented in either the published or grey literatures. Those that are documented are widely dispersed and not easy to locate.

Second, developing guidance to link expertise to tasks is hampered by lack of evidence about key aspects of most knowthat and know-how, including strengths and weaknesses, effectiveness, or how well the expertise can be adapted to differing circumstances.

Third, elements of expertise in research integration and implementation will be characterised differently within and across the three realms. This is affirmed by our experience of working together as authors, where we found, for example, different framings of power relations and how they should be addressed. As well as identifying differences, it is essential to recognise when particular know-that or know-how expertise, as used by different groups, is essentially the same.

Fourth, those who currently have expertise in research integration and implementation come from very different backgrounds, so that expertise that is self-evident to some will be a revelation to others. For example, the importance of understanding and managing power relations will be obvious to those originally trained in the social sciences, but will be a topic some others rarely consider. Similarly, the possibility of non-linear relations between two causal factors will be self-evident to those originally trained in the physical sciences, but new to many others.

As hinted at in these examples, there are many areas where expertise in research integration and implementation intersects with expertise in existing disciplines. How this is dealt with in deciding what expertise to include in a compilation of know-that and know-how for research integration and implementation requires careful consideration.

Finally, the biggest challenge in compiling and assessing expertise, as well as writing guidance notes, is that no single individual or group has experience across the three realms, or even a significant subset. Instead, a more labour-intensive and timeconsuming process is necessary, requiring individuals and groups from the different realms to work together globally to understand each other's contributions, before being able to undertake the requisite sifting, assessing and provision of guidance.

It is beyond the scope of this article to do more than flag these matters. Nevertheless, we see the challenges as both intellectually exciting and practical, although far from straight-forward to manage.

Building on positive trends. Growing recognition of connections across different specific approaches is a positive trend, especially for identifying the broad range of expertise to be included in a knowledge bank. For example, the Oxford Handbook of Interdisciplinarity (Frodeman, 2017) includes information on transdisciplinarity, systems thinking, design science, team science, sustainability science, integration and implementation sciences, and innovation, along with its primary focus on interdisciplinarity. Similarly, the Sage Handbook of Action Research (Bradbury, 2015) provides chapters on systems thinking and integration and implementation sciences. In the same vein, the journal GAIA has published a series of Toolkits for Transdisciplinarity (Bammer, 2017) and is now issuing a series of Frameworks for Transdisciplinary Research that are drawing connections, not only to other specific approaches such as systems thinking, change management and integration and implementation sciences (e.g., Cabrera and Cabrera, 2018 on systems thinking), but also to dialogue and collaboration methods from case-based experience (e.g., Bammer, 2016b; McDonald et al., 2009). 
Indexing and organising the expertise and making it widely accessible. Compiling expertise is not enough. The knowledge bank needs to be organised in a way that makes expertise easy to find by a wide range of interested individuals, teams and communities of practice, as both contributors and users. Multiple entry points are required, providing access that is intuitive and welcoming, and that accommodates the different ways of understanding and tackling complex societal and environmental problems described in this article.

Finding an effective way to index expertise in the knowledge bank is key. This formidable challenge calls for collaboration with information scientists to build on lessons from existing knowledge banks and cyberinfrastructures, including Wikipedia (2019), Dryad Digital Repository (2019), Open Biological and Biomedical Ontology (OBO) Foundry (2019), Gene Ontology Resource (2019), as well as the Long-Term Ecological Research Network (2019) and the National Ecological Observatory Network (2019). In addition, Leonelli and Ankeny (2015, p. 703) highlight a 'tension between the stability and the flexibility of classificatory categories,' which need both consistency over time and to be adapted and updated so that they 'mirror the research practices and knowledge of their users'.

A host of other practical matters must also be resolved, including funding, maintaining long-term integrity and interoperability, establishing meta-data standards, encompassing burgeoning variations in nomenclature, determining who can contribute and how, providing credit and other incentives to contribute, and establishing standards for assessment of contributions. Again, how such challenges are addressed by existing successful repositories will be instructive. For example, Wikipedia (2019) is the best-known online reference website and provides lessons about a resource written collaboratively by volunteers. Its open authorship and editing policy mean new content can be easily created and all content can be kept up-to-date, but it also means accuracy, rigour and indexing can be inconsistent.

Building on positive trends. A positive trend to build on is the activities of Integration and Implementation Sciences (i2S; Bammer, 2013), which is testing ideas relevant to developing an ontology. The i2S frame consists of three domains: synthesis of disciplinary and stakeholder knowledge, understanding and managing diverse unknowns, and providing integrated research support for policy and practice change. It also addresses five questions: For what and for whom? Of what? How? Context? Outcome? These questions encompass specific knowledge and skills in integration and implementation, such as framing, modelling and co-production. In the aggregate, these components aim to provide a structure or ontology for indexing, codified in a repository of resources (Integration and Implementation Sciences, 2019c).

An important caveat to organising expertise into a knowledge bank is the need for congruence with the challenges of dealing with complex problems. The multiple facets and interactions of complexity, and the creativity required to deal with them, cannot be ignored or downplayed in favour of indexing requirements. Indeed, the challenges of building a knowledge bank to strengthen expertise in research integration and implementation are likely to stimulate further development of information sciences towards systems that can deal effectively with complexity.

Understanding and overcoming the core reasons for the existing fragmentation. Overcoming fragmentation of expertise in research integration and implementation requires understanding why it exists and what forces maintain it. Separate explanations offer insights into fragmentation of expertise codified by various specific approaches and of expertise developed by case-based experience that is independent of specific approaches.

Specific approaches can be seen as small 'tribes' around particular 'territories', to use concepts and terms made popular by Becher (1989) in his analysis of the construction of boundaries that differentiate disciplines. By their nature, tribes organise around certain journals and conferences, and their members become reviewers for each other's work. More broadly, members of a tribe are identified by 'traditions, customs and practices, transmitted knowledge, beliefs, morals and rules of conduct, as well as their linguistic and symbolic forms of communication and the meanings they share' (Becher, 1989, p. 24). Tribal differences among specific approaches were evident in our interactions at the 2013 conference (Integration and Implementation Sciences, 2019a) and in our deliberations as an authorship group.

As an aside, Becher's insights can be further invoked to envision that building a knowledge bank is an exercise in reviewing a territory in order to formalise permeable boundaries 'open to incoming and outgoing traffic' (1989, p. 37) with the aim of rendering accessible all elements of expertise required to tackle complex societal and environmental problems. Indeed, it was the interaction of our individual 'tribes' that exposed our group to rich 'intra-tribal' knowledge and reinforced our joint commitment to developing a knowledge bank.

The fragmentation of expertise developed by case-based experience that is independent of specific approaches can be understood through the expositions on mode 2 research underpinned by transdisciplinarity (in its generic rather than specific sense) by Gibbons et al. (1994) and on interdisciplinarity (also in its generic sense) by the US National Academies (National Academy of Sciences, National Academy of Engineering and Institute of Medicine, 2005). Both publications emphasised that, at the time they were written, relevant expertise was diffused in a loose way, typically transmitted by experienced researchers moving to new problems rather than through institutionalised reporting in professional journals. This mode of diffusion continues to be typical among those focused on case-based experience, as described earlier.

Both forces of fragmentation-multiple small tribes and loose diffusion-are reinforced by a third force combining highacademic workload and publication pressure (Kinman, 2014; Kinman and Jones, 2003). This combination severely limits the time researchers have to look beyond their own tribe or accumulated experience to find useful know-that and knowhow expertise, especially when doing so requires familiarity with a wide array of literature and multiple specialised 'languages.'

Building on positive trends. At least three encouraging trends are overcoming fragmentation. First, 'borrowing' (i.e., taking concepts and methods from one discipline into another) has long been an acknowledged feature of interdisciplinary research (Klein, 1990). In addition, it occurs across specific approaches. For example, the interdisciplinary tool "Toolbox' dialogue method to uncover research worldviews' (see Box 2) has been incorporated into an online toolkit of co-production methods for transdisciplinary research (td-Net, 2019). Borrowing is also starting to link case-based experience with specific approaches. Population health research, for instance, is adapting ideas from complexity science (Long et al., 2018; Thompson et al., 2016).

A second trend is exemplified by the Integration and Implementation Insights blog (2019), which is a conduit for linking researchers, regardless of tribe or problem tackled, allowing them to share integration and implementation expertise in easy-to-read form. This is in line with the community building 
identified by Leonelli and Ankeny (2015) as an essential component of developing a large-scale repository.

A third trend builds on the long-standing practice of establishing dedicated centres, employing a range of disciplinary experts, to address complex societal and environmental issues. The heads of such organisations are forming an authoritative leadership group to ensure funders and research policy makers understand, value and support expertise in research integration and implementation (Network of Interdisciplinary and Transdisciplinary Research Organisations-Oceania, 2019; Palmer, 2018).

\section{Final considerations}

To address societal and environmental problems through the sustainable development goals, effective illicit drugs policy, action on spiralling health care costs and other initiatives, a better understanding is required of expertise in research integration and implementation, along with the ability to readily access that expertise. In this article we seek to rally those who have developed elements of that expertise around the tasks of defining expertise, making it visible and accessible, and organising to ensure that it is rewarded. What is required is a major effort by the relevant communities and teams. In this article we have sought to tread the fine line between proposing these ideas with enough detail to be comprehensible, while leaving them open to amendment by those who need to be involved in codifying expertise in research integration and implementation.

We have sought to lay foundations for the work of systematising expertise by discussing:

- when expertise is needed in tackling complex societal and environmental problems

- the realms where it can currently be found and who therefore needs to be represented

- how expertise could be strengthened by being organised in a knowledge bank.

To realise the vision of codified expertise requires a virtuous cycle between developing an accessible, widely known, dynamic knowledge bank and successes based on improved research and action on complex societal and environmental problems (Fig. 1).

In particular, building a knowledge bank to strengthen expertise in research integration and implementation has the potential to:

- improve access to, and application of, the most effective know-that and know-how contributory expertise

- provide more and new opportunities for building expertise, along with enhancing its quality by identifying gaps in expertise and assessment of strengths and weaknesses, effectiveness and adaptability

- facilitate break-through innovation in tackling complex societal and environmental problems.

These goals share the common aim of achieving greater tractability and success in tackling complex societal and environmental problems. In turn, accumulating success, with wellworked through examples of how this rests on effective research integration and implementation, has the potential to:

- increase demand for relevant expertise, along with interest in developing capacity and capability in research integration and implementation

- increase support and justification for evaluation of expertise to improve its quality and provide a stronger evidence base for its appropriate use

- build institutional support for using and further developing the knowledge bank, manifested in funding to sustain it, training for users, and recognition of expertise in research

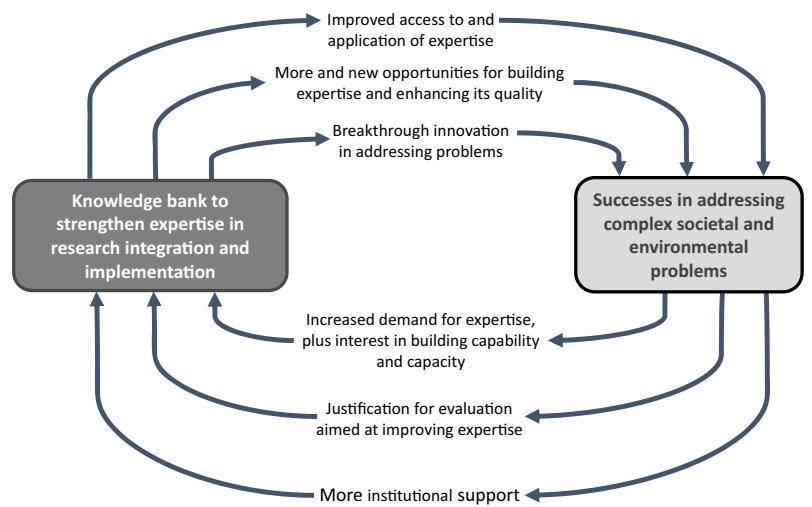

Fig. 1 Mutual reinforcement (a virtuous cycle) between a knowledge bank to strengthen expertise in research integration and implementation and success in addressing complex societal and environmental problems.

integration and implementation in faculty hiring and promotion processes.

However, none of this can happen without the effort to define, identify and gather expertise. Unless there is continual input into the knowledge bank, the feedback loop can become a stagnant trap, miring the system in its own inertia. Expertise stays limited, few opportunities for building expertise arise, quality remains low and no break-through innovations occur. As a result, few successes in addressing complex societal and environmental problems accumulate, so that there is no increased interest and demand for expertise, little justification for evaluation efforts and lack of institutional support.

Avoiding the stagnation trap and the graveyard for ideas that did not gain traction requires a large cohort of committed proponents, substantial funding and a process for building the knowledge bank guided by principles that frame pursuit of robust workable outcomes for complex problems, especially eliciting and respecting diverse perspectives, fostering curiosity, managing systems with many unknowns and supporting on-going learning. The aim is to make construction of a knowledge bank a fulfilling social process, building community and connections while supporting the community in becoming more skilled and responsive to challenges and change. In that respect, the knowledge bank and the community would co-evolve.

The long-term vision is an institutionalised knowledge bank that serves not only researchers, but also practitioners, policy makers, and other stakeholders concerned with improving research-based understanding and action on complex societal and environmental problems. In particular, the knowledge bank will be an essential resource about expertise for funders of research on complex societal and environmental problems, as well as scientific journal editors and reviewers who judge the quality of such research and its applications. Further, it will have widespread use in university teaching and continuing education. In summary, we envision building a major resource that is a recognised and accepted part of the global research environment.

Received: 20 May 2019; Accepted: 27 November 2019; Published online: 13 January 2020

\section{References}

Ackoff RL (1974) Redesigning the future. A systems approach to societal problems. Wiley, New York, NY

Ackoff RL (1981) Creating the corporate future. Wiley, New York, NY

Adner R (2012) The wide lens. Penguin, London 
Aven T (2012) Foundations of risk analysis, 2nd edn. Wiley, Chichester

Babor T, Caulkins J, Fischer B, Foxcroft D, Humphreys K, Medina-Mora M, Obot I, Rehm J, Reuter P, Room R, Rossow I, Strang J (2018) Drug policy and the public good, 2nd edn. Oxford University Press, Oxford

Bammer G (2013) Disciplining interdisciplinarity: Integration and implementation sciences for researching complex real-world problems. ANU Press, Canberra, https://doi.org/10.22459/DI.01.2013

Bammer G (2016a) What constitutes appropriate peer review for interdisciplinary research? Palgrave Commun 2(16017). https://doi.org/10.1057/ palcomms.2016.17

Bammer G (2016b) Toolkits for transdisciplinarity-Toolkit \#3: dialogue methods for knowledge synthesis. GAIA 25(1):7. https://doi.org/10.14512/gaia.25.1.3

Bammer G (2017) Eight toolkits for transdisciplinarity. Originally published in the journal GAIA. Available online at https://www.oekom.de/fileadmin/ zeitschriften/gaia_Grafiken/GAIA_Flyer_Toolkits.pdf

Becher T (1989) Academic tribes and territories: Intellectual enquiry and the cultures of disciplines. The Society for Research into Higher Education \& Open University Press, Milton Keynes

Beer S (1984) The viable system model: Its provenance, development, methodology and pathology. J Operational Res Soc 35:7-25

Beishon J, Peters G (1972) Systems behaviour. Harper and Row, London

Ben-Haim Y (2006) Info-Gap decision theory: Decisions under severe uncertainty, 2nd edn. Academic Press, London

Bennett LM, Gadlin H, Marchand C (2018) Collaboration and team science field guide, 2nd edn. National Institutes of Health Publication No. 18-7660. National Cancer institute, Bethesda, https://www.cancer.gov/about-nci/ organization/crs/research-initiatives/team-science-field-guide

Bergmann M, Jahn T, Knobloch T, Krohn W, Pohl C, Schramm E (2012) Methods for transdisciplinary research. A primer for practice. Campus Verlag, Frankfurt

Bioenergy Research, Development \& Extension Advisory Forum and Technical Working Groups (2014) Opportunities for primary industries in the bioenergy sector: National research, development and extension strategy. Rural Industries Research and Development Corporation, Canberra, https://www. agrifutures.com.au/wp-content/uploads/publications/11-079.pdf

Biggs R, Schlüter M, Schoon ML (2015) An introduction to the resilience approach and principles to sustain ecosystem services in social-ecological systems. In: Biggs R, Schlüter M, Schoon ML (eds) Principles for building resilience: Sustaining ecosystem services in social-ecological systems. Cambridge University Press, Cambridge, pp 1-31

Bradbury H (ed) (2015) The SAGE handbook of action research, Third edn. Sage, Los Angeles

British Academy Working Group on Interdisciplinarity (2016) Crossing paths: Interdisciplinary institutions, careers, education and applications. The British Academy for the Humanities and Social Sciences, London, https://www. thebritishacademy.ac.uk/sites/default/files/Crossing\%20Paths\%20-\%20Full\% 20Report.pdf

Bromham L, Dinnage R, Hua X (2016) Interdisciplinary research has consistently lower funding success. Nature 534(June):684-687

Buckley W (1965) Modern systems research for the behavioral scientist. Aldine, Chicago

Bursztyn M, Drummond J (2014) Sustainability science and the university: Pitfalls and bridges to interdisciplinarity. Environ Educ Res 20(3):313-332. https:// doi.org/10.1080/13504622.2013.780587

Cabrera D, Cabrera L (2018) Four building blocks of systems thinking. Frameworks for transdisciplinary research \#4. GAIA 27(2):200. https://doi.org/ 10.14512/gaia.27.2.3

Cairney P, Weible CM (2017) The new policy sciences: Combining the cognitive science of choice, multiple theories of context, and basic and applied analysis. Policy Sci 50(4):619-627. https://doi.org/10.1007/s11077-017-9304-2

Checkland P (1981) Systems thinking, systems practice. Wiley, Chichester

Churchman CW (1970) Operations research as a profession. Manag Sci 17:B37-53

Churchman CW (1979) The systems approach, 2nd edn. Dell, New York, NY

Cicmil SJK, Cooke-Davies TJ, Crawford LH, Richardson KA (2009) Exploring the complexity of projects: Implications of complexity theory for project management practice. Project Management Institute, Newtown Square, PA

Cilliers P (1998) Complexity and postmodernism: Understanding complex systems. Routledge, Abingdon

Clark WC, Dickson NM (2003) Sustainability science: The emerging research program. Proc Natl Acad Sci USA 100(14): 8059-8061

Collins H, Evans R (2002) The third wave of science studies: Studies of expertise and experience. Soc Stud Sci 32:235-296

Collins H, Evans R (2007) Rethinking expertise. University of Chicago Press, Chicago

Crawford DF, O'Connor MH, Jovanovic T, Herr A, Raison RJ, O'Connell DA, Baynes T (2016) A spatial assessment of potential biomass for bioenergy in Australia in 2010, and possible expansion by 2030 and 2050. Glob Change Biol Bioenergy 8:707-722. https://doi.org/10.1111/gcbb.12295 de Sadeleer N (ed) (2007) Implementing the precautionary principle: Approaches from the Nordic Countries, EU and USA. Earthscan, London

Dorst K (2015) Frame innovation. MIT Press, Cambridge

Dryad Digital Repository (2019) [online] Available at: http://datadryad.org/ [Accessed 12 Mar 2019]

Eccles MP, Armstrong D, Baker P, Cleary K, Davies H, Davies S, Glasziou P, Ilott I, Kinmonth A-L, Leng G, Logan S, Marteau T, Michie S, Rogers H, RycroftMalone J, Sibbald B (2009) An implementation research agenda. Implement Sci 4:18, http://www.implementationscience.com/content/4/1/18

Elsum I (2013) Tackling integrative applied research: Lessons from the management of innovation (Commentary). In: Bammer G (ed) Disciplining interdisciplinarity: Integration and implementation sciences for researching complex real-world problems. ANU Press, Canberra, pp. 431-439

Emery FE (1969) Systems thinking. Volume 1. Penguin, Harmondsworth

Emery FE (1981) Systems thinking. Volume 2. Penguin, Harmondsworth

Farine DR, O'Connell DA, Raison RJ, May BM, O'Connor MH, Crawford DF, Herr A, Taylor JA, Jovanovic T, Campbell PK, Dunlop MIA, Rodriguez LC, Poole ML, Braid AL, Kriticos D (2012) An assessment of biomass for bioelectricity and biofuel, and for greenhouse gas emission reduction in Australia. Glob Change Biol Bioenergy 4:148-175

Fleming L (2007) Breakthroughs and the long tail of innovation. MIT Sloan Manag Rev 49:69-74

Flood RL, Jackson MC (eds) (1991) Critical systems thinking: Directed readings. Wiley, Chichester

Flood RL, Romm NRA (eds) (1996) Critical systems thinking: Current research and practice. Plenum, New York, NY

Forrester JW (1961) Industrial dynamics. MIT Press, Cambridge MA

Fortune J, Peters G (1995) Learning from failure: The systems approach. Wiley, Chichester

François C (2004) International encyclopedia of systems and cybernetics, 2nd edn. K G Saur, Muenchen

Frantzeskaki N, Hölscher K, Holman IP, Pedde S, Jaeger J, Kok K, Harrison PA (2019) Transition pathways to sustainability in greater than $2^{\circ} \mathrm{C}$ climate futures of Europe. Regional Environ Change 19:777-789. https://doi.org/ 10.1007/s10113-019-01475-x

Friend J, Hickling A (2005) Planning under pressure: The strategic choice approach, 3rd edn. Routledge, London

Frodeman R (2017) (ed in chief), Klein JT, Pacheco RCS (associate eds) The Oxford handbook of interdisciplinarity. 2nd edn. Oxford University Press: Oxford

Fulton EA, Smith ADM, Smith DC, Johnson P (2014) An integrated approach is needed for ecosystem based fisheries management: Insights from ecosystemlevel management strategy evaluation. PLoS ONE 9:e84242. https://doi.org/ 10.1371/journal.pone.0084242

Funtowicz SO, Ravetz JR (1993) Science for the post-normal age. Futures 25 (Sept):739-755

Gassmann O, Zeschky M (2008) Opening up the solution space: The role of analogical thinking for breakthrough product innovation. Creativity Innov Manag 17:97-106

Gene Ontology Resource (2019) The gene ontology resource. [online] Available at: http://geneontology.org/ [Accessed 18 Apr 2019]

Gertler PJ, Martinez S, Premand P, Rawlings LB, Vermeersch CMJ (2016) Impact evaluation in practice, 2nd edn. Inter-American Development Bank and World Bank, Washington, DC, http://www.worldbank.org/ieinpractice

Gibbons M, Limoges C, Nowotny H, Schwartzman S, Scott P, Trow M (1994) The new production of knowledge. The dynamics of science and research in contemporary societies. Sage, London

Gobet F (2015) Understanding expertise: A multidisciplinary approach. Palgrave, London

Gorddard R, Colloff MJ, Wise RM, Ware D, Dunlop M (2016) Values, rules and knowledge: Adaptation as change in the decision context. Environ Sci Policy 57:60-69

Graham P, Reedman L, Rodriguez L, Raison J, Braid A, Haritos V, Brinsmead T, Hayward J, Taylor J, O'Connell D (2011) Sustainable aviation fuels road map: Data assumptions and modelling. CSIRO, Australia

Hall AD (1962) A methodology for systems engineering. Van Nostrand, Princeton

Haryanto B (2013) Applying the I2S framework to air pollution and health in Indonesia (Commentary). In: Bammer G (ed) Disciplining interdisciplinarity: Integration and implementation sciences for researching complex real-world problems. ANU Press, Canberra, pp. 389-395

Hayward JA, O'Connell DA, Raison RJ, Warden AC, O'Connor MH, Murphy HT, Booth TH, Braid AL, Crawford DF, Herr A, Jovanovic T, Poole ML, Prestwidge D, Raisbeck-Brown N, Rye L (2015) The economics of producing sustainable aviation fuel: a regional case study in Queensland, Australia Global Change Biology. Glob Change Biol Bioenergy 7:497-511. https://doi org/10.1111/gcbb.12159

Hess DJ (2016) Undone science. Social movements, mobilized publics, and industrial transitions. MIT Press, Cambridge MA 
Hirsch Hadorn G, Hoffmann-Riem H, Biber-Klemm S, Grossenbacher-Mansuy W, Joye D, Pohl C, Wiesmann U, Zemp E (eds) (2008) Handbook of transdisciplinary research. Springer, New York, NY

Holling CS (1978) Adaptive environmental assessment and management. John Wiley \& Sons, Chichester

Horn RE, Weber RP (2007) New tools for resolving wicked problems: mess mapping and resolution mapping processes. http://www.strategykinetics. com/files/New_Tools_For_Resolving_Wicked_Problems.pdf

Hughes TP, Gunderson L, Folke C, Baird A, Bellwood D, Berkes F, Crona B, Helfgott A, Leslie H, Norberg J, Nystrom M, Olsson P, Österbloom H, Scheffer M, Schuttenberg H, Steneck RS, Tengö M, Troell M, Walker B, Wilson J, Worm B (2007) Adaptive management of the Great Barrier Reef and the Grand Canyon World Heritage Areas. Ambio 36:586-592

Integration and Implementation Insights (2019) [online] Available at: http:// i2Insights.org [Accessed 18 Apr 2019]

Integration and Implementation Sciences (2019a) First i2S conference [online] Available at: http://i2s.anu.edu.au/what-i2s/first-i2s-conference [Accessed 18 Apr 2019]

Integration and Implementation Sciences (2019b) Professional associations and networks. [online] Available at: http://i2s.anu.edu.au/resources/ associations_networks [Accessed 18 Apr 2019]

Integration and Implementation Sciences (2019c) Resources. [online] Available at: http://i2s.anu.edu.au/resources [Accessed 18 Apr 2019]

International Standards Association (ISO); 2015 ISO 13065:2015 Sustainability criteria for bioenergy. [online] Available at: https://www.standards.org.au/ standards-catalogue/international/iso-slash-tmbg/iso-13065-colon-2015 [Accessed 18 Apr 2019]

Jacob WJ (2015) Interdisciplinary trends in higher education. Palgrave Commun 1:15001. https://doi.org/10.1057/palcomms.2015.1

Jahn T, Bergmann M, Keil F (2012) Transdisciplinarity: Between mainstreaming and marginalization. Ecol Econ 79:1-10. https://doi.org/10.1016/j. ecolecon.2012.04.017

Johnson MP (ed) (2012) Community-based operations research: Decision modeling for local impact and diverse populations. Springer, New York, NY

Kerwin A (1993) None too solid: medical ignorance. Knowl: Creation, Diffus, Utilisation 15(2):166-185

Kinman G (2014) Doing more with less? Work and wellbeing in academics. Somatechnics 4:219-235

Kinman G, Jones F(2003) 'Running up the down escalator': Stressors and strains in UK academics Qual High Educ 9:21-38. https://doi.org/10.1080/ 13538320308162

Klein JT (1990) Interdisciplinarity: History, theory and practice. Wayne State University Press, Detroit

Klein JT (2010) Creating interdisciplinary campus cultures. Jossey Bass and the Association of American Colleges and Universities, San Francisco

Klein JT, Falk-Krzesinski HJ (2017) Interdisciplinary and collaborative work: Framing promotion and tenure practices and policies. Res Policy 46 (6):1055-1061

Kleindorfer PR, Kunreuther HC, Schoemaker PJH (1993) Decision sciences: An integrative perspective. Cambridge University Press, Cambridge

Kriebel D, Tickner J, Epstein P, Lemons J, Levins R, Loechler EL, Quinn M, Rudel R, Schettler T, Stoto M (2001) The precautionary principle in environmental science. Environ Health Perspect 109:871-876

Ledford H (2015) Team science. Nature 525(Sept):308-311

Leonelli S, Ankeny RA (2015) Repertoires: how to transform a project into a research community. Bioscience 65(7):701-708. https://doi.org/10.1093/ biosci/biv061

Long KM, McDermott F, Meadows GN (2018) Being pragmatic about healthcare complexity: our experiences applying complexity theory and pragmatism to health services research. BMC Med 1:94. https://doi.org/10.1186/s12916-0181087-6

Long Term Ecological Research (LTER) Network (2019) [online] Available at: https://lternet.edu/ [Accessed 18 Apr 2019]

Loorbach D, Frantzeskaki N, Avelino F (2017) Sustainability transitions research: transforming science and practice for societal change. Annu Rev Environ Resour 42:599-626. https://doi.org/10.1146/annurev-environ-102014-021340

Lyall C (2019) Being an interdisciplinary academic: How institutions shape university careers. Palgrave Macmillan, Cham

Marchau VAWJ, Walker WE, Bloemen PJTM, Popper SW (eds) (2019) Decision making under deep uncertainty: From theory to practice. Springer, Cham, https://link.springer.com/book/10.1007/978-3-030-05252-2

Maru Y, O'Connell D, Grigg N, Abel N, Cowie A, Stone-Jovicich S, Butler J, Wise R, Walker B, Belay M, Fleming A, Meharg S, Meyers J (2017) Making 'resilience', 'adaptation' and 'transformation' real for the design of sustainable development projects: piloting the Resilience, Adaptation Pathways and Transformation Assessment (RAPTA) framework in Ethiopia. CSIRO, Canberra
McDonald D, Bammer G, Deane P (2009) Research integration using dialogue methods. ANU Press, Canberra, https://doi.org/10.22459/RIUDM.08.2009

McLeisch T, Strang V (2016) Evaluating interdisciplinary research: the elephant in the peer-reviewers' room. Palgrave Commun 2:16055. https://doi.org/ 10.1057/palcomms.2016.55

Mendizabal E (2010) The Alignment, Interest and Influence Matrix (AIIM) toolkit. Guidance Note. Research and Policy in Development (RAPID), Overseas Development Institute (ODI), London, https://www.odi.org/publications/ 5288-stakeholder-engagement-stakeholder-analysis-aiim-alignment-interestinfluence-matrix-roma

Michaels D (2008) Doubt is their product: How industry's assault on science threatens your health. Oxford University Press, Oxford

Midgley G (2000) Systemic intervention: philosophy, methodology, and practice. Kluwer Academic/Plenum Publishers, New York, NY

Midgley G (2003) Systems thinking (Volumes I-IV). Sage, London

Midgley G, Ochoa-Arias AE (eds) (2004) Community operational research: OR and systems thinking for community development. Kluwer Academic/Plenum Publishers, New York, NY

Miser HJ, Quade ES (eds) (1985) Handbook of systems analysis: overview of uses, procedures, applications and practice. Elsevier, New York, NY

Miser HJ, Quade ES (eds) (1988) Handbook of systems analysis: Craft issues and procedural choices. Wiley, New York, NY

Mitchell M (2009) Complexity: a guided tour. Oxford University Press, Oxford

National Academy of Sciences, National Academy of Engineering \& Institute of Medicine (2005) Facilitating interdisciplinary research. National Academies Press, Washington DC

National Ecological Observatory Network (2019) [online] Available at: http://www. neoninc.org [Accessed 18 Apr 2019]

National Research Council (2015) Enhancing the effectiveness of team science. National Academies Press, Washington, DC

Nauheimer H (1997) The change management toolbook. A collection of tools, methods and strategies. Open access pdf at http://www.change-managementtoolbook.com

Network of Interdisciplinary and Transdisciplinary Research Organisations-Oceania (2019) [online] Available at https://nitro-oceania.net/ [Accessed 26 Aug 2019]

Neuhauser L (2018) Practical and scientific foundations of transdisciplinary research and action. In: Fam D, Neuhauser L, Gibbs P (eds) Transdisciplinary theory, practice and education: the art of collaborative research and collective learning Springer, Cham, pp. 25-38

Nicholas J, Ledwith A, Bessant J (2013) Reframing the search space for radical innovation. Res Technol Manag 56:27-35

O'Connell D, Haritos VS (2010) Conceptual investment framework for biofuels and biorefineries research and development. Biofuels 1:201-216

O'Connell D, Haritos V, Graham S, Farine D, O'Connor M, Batten D, May B, Raison J, Braid A, Dunlop M (2007) Bioenergy, bioproducts and energy: a framework for research and development. Rural Industries Research and Development Corporation, Canberra

O'Connell D, Braid A, Raison J, Handberg K, Cowie A, Rodriguez L, George B (2009) Sustainable production of bioenergy: A review of global bioenergy sustainability frameworks and assessment systems. Rural Industries Research and Development Corporation, Canberra

O'Connell D, Braid A, Raison J, Hatfield-Dodds S, Wiedmann T, Cowie A, Littleboy A, Clark M (2013) Navigating sustainability: measurement, evaluation and action. CSIRO, Australia, https://www.betterevaluation.org/sites/default/ files/Navigating\%20sustainability\%20report.pdf

Open Biological and Biomedical Ontology (OBO) Foundry (2019) [online] Available at: http://www.obofoundry.org/ [Accessed 18 Apr 2019]

Oreskes N, Conway E (2010) Merchants of doubt. How a handful of scientists obscured the truth on issues from tobacco smoke to global warming. Bloomsbury, London

O'Rourke M, Crowley S (2013) Philosophical intervention and cross-disciplinary science: The story of the Toolbox Project. Synthese 190:1937-1954

Palmer L (2018) Meeting the leadership challenges for interdisciplinary environmental research. Nat Sustainability 1:330-333. https://doi.org/10.1038/ s41893-018-0103-3

Pohl C, Hirsch Hadorn G (2007) Principles for designing transdisciplinary research. Proposed by the Swiss Academies of Arts and Sciences. Oekom, Munich

PNAS Proceedings of the National Academy of Sciences of the United States of America (2019) Sustainability science. [online] Available at http:// sustainability.pnas.org/ [Accessed 26 Aug 2019]

Reckling FJ, Fischer C (2010) Factors influencing approval probability in Austrian Science Fund (FWF) decision-making procedures-FWF stand-alone projects programme, 1999 to 2008 . Available at SSRN (Social Science Research Network): https://doi.org/10.2139/ssrn.1725985

Rice M, O'Connor G, Pierantozzi R (2008) Implementing a learning plan to counter project uncertainty. MIT Sloan Manag Rev 49(2):54-62 
Richardson GP, Andersen DF (2010) Systems thinking, mapping, and modeling for group decision and negotiation. In: Eden C, Kilgour DN (eds) The handbook for group decision and negotiation. Springer, Dordrecht, pp. 313-324

Rittel HWJ, Webber MM (1973) Dilemmas in a general theory of planning. Policy Sci 4:155-169

Ritter A, King T, Lee N eds. (2017) Drug use in Australian society, 2nd edn. Oxford University Press, South Melbourne

Rotmans J, Van Asselt M (1996) Integrated assessment: growing child on its way to maturity. An editorial essay. Climatic Change 34:327-336

Savino T, Petruzzelli A, Albino V (2017) Search and recombination process to innovate: A review of the empirical evidence and a research agenda. Int J Manag Rev 19:54-75

Shaxson L, with Bielak A, Ahmed I, Brien D, Conant B, Fisher C, Gwyn E, Klerkx L, Middleton A, Morton S, Pant L, Phipps D (2012) Expanding our understanding of $\mathrm{K}^{*}(\mathrm{KT}, \mathrm{KE}, \mathrm{KTT}, \mathrm{KMb}, \mathrm{KB}, \mathrm{KM}$, etc.) A concept paper emerging from the $\mathrm{K}^{\star}$ conference held in Hamilton, Ontario, Canada, April 2012. United National University Institute of Water, Environment and Health: Hamilton, Ontario. https://assets.publishing.service.gov.uk/media/ 57a08a6e40f0b649740005ba/

KStar_ConceptPaper_FINAL_Oct29_WEBsmaller.pdf

Simon H (1996) The sciences of the artificial, 3rd edn. MIT Press, Cambridge MA

Smithson M (1989) Ignorance and uncertainty: Emerging paradigms. Springer Verlag, New York, NY

Smithson M (1999) Conflict aversion: preference for ambiguity vs. conflict in sources and evidence. Organ Behav Hum Decis Process 79:179-198

Smithson M, Ben-Haim Y (2015) Reasoned decision making without math? Adaptability and robustness in response to surprise. Risk Anal 35:1911-1918

Sterman JD (2000) Business dynamics. Systems thinking and modeling for a complex world. McGraw-Hill Higher Education, Boston

Stevens A (2010) Drugs, crime and public health: The political economy of drug policy. Routledge-Cavendish, London

Taha HA (2017) Operations research: An introduction, 10th edn. Pearson, Harlow

Td-Net (Network for transdisciplinary research) (2019) Methods and tools for coproducing knowledge. [online] Available at: https://naturalsciences.ch/topics/ co-producing_knowledge [Accessed 18 Apr 2019]

Therival R, Wood G (eds) (2018) Methods of environmental and social impact assessment, 4th edn. Routledge, New York, NY

Third National Health Assembly (2010) NHA3/Resolution 8 Medical hub policy. [online] Available at: https://en.nationalhealth.or.th/wp-content/uploads/ 2017/09/Medical-Hub-Resolution.pdf (English) https://www.samatcha.org/ sites/default/files/document/0304-Res-3-4.pdf (Thai) [Accessed $18 \mathrm{Apr}$ 2019]

Thompson DS, Fazio X, Kustra E, Patrick L, Stanley D (2016) Scoping review of complexity theory in health services research. BMC Health Serv Res 16:87. https://doi.org/10.1186/s12913-016-1343-4

Toolbox Dialogue Initiative (2019) [online] Available at: http://tdi.msu.edu/ [Accessed 18 Apr 2019]

Ulrich W (1983) Critical heuristics of social planning: a new approach to practical philosophy. Haupt, Berne

Vennix JAM (1996) Group model building: facilitating team learning using system dynamics. Wiley, Chichester

Vilsmaier U, Brandner V, Engbers M (2017) Research in-between: The constitutive role of cultural differences in transdisciplinarity. The Transdisciplinary J Eng Sci 8:169-179
Wikipedia (2019) Wikipedia: About. [online] Available at: https://en.wikipedia.org/ wiki/Wikipedia:About [Accessed 18 Apr 2019]

Young J, Shaxson L, Jones H, Hearn S, Datta A, Cassidy C (2014) Rapid outcome mapping approach: A guide to policy engagement and influence. Overseas Development Institute, London, https://www.odi.org/sites/odi.org.uk/files/ odi-assets/publications-opinion-files/9011.pdf

\section{Acknowledgements}

This article has its origins in the 2013 First Global Conference on Research Integration and Implementation (Integration and Implementation Sciences 2019a), which brought together the authors and specifically drew on all three realms of expertise. The conference was supported by the Australian Research Council Centre of Excellence on Policing and Security and The Australian National University. Co-conferences in Germany, The Netherlands and Uruguay were, respectively, sponsored by Leuphana University of Lueneburg; the Centre for Innovation at Campus The Hague, Leiden University; and the Espacio Interdisciplinario, Universidad de la República. Contributions by Robyn Mildon, Dean Fixsen, Alison Ritter and Noshir Contractor at the conference informed the development of this article and valuable feedback on earlier versions was received from $\mathrm{L}$. David Brown, Sharon Friel, Cynthia Mitchell, Christian Roth and Judith Sutz. Assistance was provided by Peter Deane and David McDonald on aspects of the literature, as well as Erin Walsh on the figure.

\section{Competing interests}

The authors declare no competing interests.

\section{Additional information}

Correspondence and requests for materials should be addressed to G.B.

Reprints and permission information is available at http://www.nature.com/reprints

Publisher's note Springer Nature remains neutral with regard to jurisdictional claims in published maps and institutional affiliations.

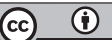

Open Access This article is licensed under a Creative Commons Attribution 4.0 International License, which permits use, sharing, adaptation, distribution and reproduction in any medium or format, as long as you give appropriate credit to the original author(s) and the source, provide a link to the Creative Commons license, and indicate if changes were made. The images or other third party material in this article are included in the article's Creative Commons license, unless indicated otherwise in a credit line to the material. If material is not included in the article's Creative Commons license and your intended use is not permitted by statutory regulation or exceeds the permitted use, you will need to obtain permission directly from the copyright holder. To view a copy of this license, visit http://creativecommons.org/ licenses/by/4.0/
\end{abstract}

(c) The Author(s) 2020

Gabriele Bammer (1,2*, Michael O'Rourke $0^{3}$, Deborah O'Connell ${ }^{4}$, Linda Neuhauser ${ }^{5}$, Gerald Midgley $6,7,8,9,10,11$, Julie Thompson Klein ${ }^{12,13}$, Nicola J. Grigg $\oplus^{4}$, Howard Gadlin ${ }^{14}$, Ian R. Elsum $\oplus^{15,16}$, Marcel Bursztyn $\circledast^{17,18}$, Elizabeth A. Fulton ${ }^{19,20}$, Christian Pohl13,21, Michael Smithson ${ }^{22}$, Ulli Vilsmaier ${ }^{23}$, Matthias Bergmann 24,25 , Jill Jaeger ${ }^{26}$, Femke Merkx ${ }^{27}$, Bianca Vienni Baptista ${ }^{13}$, Mark A. Burgman ${ }^{28}$, Daniel H. Walker ${ }^{29}$, John Young ${ }^{30}$, Hilary Bradbury ${ }^{31}$, Lynn Crawford $32,33,34$, Budi Haryanto (1) ${ }^{35}$, Cha-aim Pachanee ${ }^{36}$, Merritt Polk ${ }^{37} \&$ George P. Richardson ${ }^{38}$

${ }^{1}$ Research School of Population Health, The Australian National University, Canberra, ACT, Australia. ${ }^{2}$ Institute for Advanced Sustainability Studies, Potsdam, Germany. ${ }^{3}$ Center for Interdisciplinarity and Department of Philosophy, Michigan State University, East Lansing, MI, USA. ${ }^{4}$ CSIRO Land and Water, Canberra, ACT, Australia. ${ }^{5}$ Health Research for Action Center, School of Public Health, University of California, Berkeley, CA, USA. ${ }^{6}$ Centre for Systems Studies, Business School, University of Hull, Hull, UK. ${ }^{7}$ School of Innovation, Design and Engineering, Mälardalen University, Eskilstuna, Sweden. ${ }^{8}$ Victoria Business School, Victoria University of Wellington, Wellington, New Zealand. ${ }^{9}$ School of Political and Social Sciences, University of Canterbury, Christchurch, New Zealand. ${ }^{10}$ School of Agriculture and Food Sciences, University of Queensland, Brisbane, QLD, 
Australia. ${ }^{11}$ Informatics Department, Faculty of Technology, Linnaeus University, Växjö, Sweden. ${ }^{12}$ Department of English, Wayne State University, Detroit, MI, USA. ${ }^{13}$ Transdisciplinarity Lab, Department of Environmental Systems Science, ETH Zurich, Zurich, Switzerland. ${ }^{14}$ Retired, Bethesda, MD, USA. ${ }^{15}$ Research School of Management, The Australian National University, Canberra, ACT, Australia. ${ }^{16}$ Centre for Transformative Innovation, Swinburne University of Technology, Melbourne, VIC, Australia. ${ }^{17}$ Center for Sustainable Development, University of Brasília, Brasília, Brazil. ${ }^{18}$ INCT/Odisseia-Observatory of Socio-environmental Dynamics, Brasília, Brazil. ${ }^{19}$ CSIRO Oceans and Atmosphere, Hobart, TAS, Australia. ${ }^{20}$ Centre for Marine Socioecology, University of Tasmania, Hobart, TAS, Australia. ${ }^{21}$ td-net, Swiss Academies of Arts and Sciences, Bern, Switzerland. ${ }^{22}$ Research School of Psychology, The Australian National University, Canberra, ACT, Australia. ${ }^{23}$ Institute of Philosophy and Sciences of Art and Methodology Center, Leuphana University of Lueneburg, Lueneburg, Germany. ${ }^{24}$ Institute for Social-Ecological Research, Frankfurt, Germany. ${ }^{25}$ Institute for Ethics and Transdisciplinary Sustainability Research, Leuphana University of Lueneburg, Lueneburg, Germany. ${ }^{26}$ Independent Scholar, Vienna, Austria. ${ }^{27}$ Kenniscocreatie, Onderzoek \& Advies, The Hague, The Netherlands. ${ }^{28}$ Centre for Environmental Policy, Imperial College London, London, UK. ${ }^{29}$ Australian Centre for International Agricultural Research, Canberra, ACT, Australia. ${ }^{30}$ International Network for Advancing Science and Policy (INASP), Oxford, UK. ${ }^{31}$ Action Research Plus Foundation (AR+), Portland, OR, USA. ${ }^{32}$ Faculty of Engineering, The University of Sydney, Sydney, NSW, Australia. ${ }^{33}$ School of Management, Cranfield University, Cranfield, UK. ${ }^{34}$ Faculty of Society and Design, Bond University, Gold Coast, QLD, Australia. ${ }^{35}$ Department of Environmental Health, University of Indonesia, Depok, West Java, Indonesia.

${ }^{36}$ International Health Policy Program, Ministry of Public Health, Nonthaburi, Thailand. ${ }^{37}$ School of Global Studies, University of Gothenburg, Gothenburg, Sweden. ${ }^{38}$ Rockefeller College of Public Affairs and Policy, University at Albany, State University of New York, Albany, NY, USA. *email: Gabriele.Bammer@anu.edu.au 